Nghiên cứu trước đây cho thấy bệnh nhân hút thuốc sẽ có thời gian xuất hiện vôi hoá sớm hơn mười năm so với người khổng hút thuốc. Mặt khác, vôi hoá ở những người trước đây hút thuốc cũng xuất hiện sớm hơn, tuỳ thuộc vào thời gian hút thuốc và thời điểm cai thuốc và mức độ gia tăng này không có sự khác nhau về giới tính [1]. Bên cạnh đó, uống rượu có thể gây rối loạn chuyển hoá, cũng có nguy cơ gây xơ vữa và vôi hoá thành mạch. Mắt khác, thừa cân béo phì là khi chỉ số khối cơ thể BMI $\geq 23$. Chỉ số BMI cao chiếm khoảng 25-49\% bệnh động mạch vành ở các nước phát triển. Một số nghiên cứu cho thấy nguy cơ mắc bệnh động mạch vành ở nhóm béo phì cao gấp 3 lần nhóm có cân nặng bình thường.

Tuy nhiên trong nghiên cứu này, chúng tôi thây tỉ lệ vôi hoá động mạch vành ở những người uống rượu là $66,2 \%$, ở người uống hút thuốc là $66,1 \%$ và ở người béo phì là $61,8 \%$ là tương đối cao, nhưng không thấy khác biệt có ý nghĩa thống kê so với tỉ lệ VHMV ở các nhóm không mắc các nguy cơ này $(p>0,05)$. Bên cạnh đó, kết quả phân tích hồi quy logistic đa biến cũng cho thấy các trường hợp uống rượu, hút thuốc hay béo phì có nguy cơ mắc VHMV cao hơn nhưng sự khác nhau là chưa có ý nghĩa thống kê $(p>0,05)$.

\section{KẾT LUẬN}

Vôi hoá động mạch vành được phát hiện trên CLVT 256 dãy có liên quan đến một số yếu tố về lối sống và thể chất của từng cá nhân. Trong số đó, tuổi cao và nam giới là những yếu tố có liên quan đồng biến đến VHMV. Bên cạnh đó, các bệnh lý nền như cao huyết áp, đái tháo đường cũ̉ng làm gia tăng nguy cơ vôi hoá này.

\section{TÀI LIÊU THAM KHẢO}

1. Nils Lehmann, Stefan Möhlenkamp, Amir A. Mahabadi et al. (2014). Effect of smoking and other traditional risk factors on the onset of coronary artery calcification: Results of the Heinz Nixdorf recall study. Atherosclerosis, 232(2), 339-345.

2. L. S. Jamjoum, L. F. Bielak, S. T. Turner et al. (2002). Relationship of blood pressure measures with coronary artery calcification. Med Sci Monit, 8(12), Cr775-81.

3. H. H. Oei, R. Vliegenthart, A. Hofman et al. (2004). Risk factors for coronary calcification in older subjects. The Rotterdam Coronary Calcification Study. Eur Heart J, 25(1), 48-55.

4. Emil M. deGoma, Joshua W. Knowles, Fabio Angeli et al. (2012). The evolution and refinement of traditional risk factors for cardiovascular disease. Cardiology in review, 20(3), 118-129.

5. A. R. Folsom, G. W. Evans, J. J. Carr et al. (2004). Association of traditional and nontraditional cardiovascular risk factors with coronary artery calcification. Angiology, 55(6), 613-23.

6. R. L. McClelland, H. Chung, R. Detrano et al. (2006). Distribution of coronary artery calcium by race, gender, and age: results from the MultiEthnic Study of Atherosclerosis (MESA). Circulation, 113(1), 30-7.

7. A. Jeevarethinam, S. Venuraju, A. Dumo et al. (2017). Relationship between carotid atherosclerosis and coronary artery calcification in asymptomatic diabetic patients: A prospective multicenter study. Clin Cardiol, 40(9), 752-758.

8. K. Nasir, J. Rubin, M. J. Blaha et al. (2012). Interplay of coronary artery calcification and traditional risk factors for the prediction of allcause mortality in asymptomatic individuals. Circ Cardiovasc Imaging, 5(4), 467-73.

\title{
KẾT QUẢ PHỤC HỒI CHỨC NĂNG KHỚP VAI SAU PHẪU THUẬT KHÂU RÁCH CHÓP XOAY KHỚP VAI
}

\section{TÓM TẮT}

Mục tiêu: Đánh giá kết quả phục hồi chức năng khớp vai sau phẫu thuật nội soi khâu chóp xoay khớp vai. Phương pháp: can thiệp tiến cứu không có nhóm chứng; chọn mẫu toàn bộ được 58 người bệnh

\footnotetext{
*Bênh viện Việt Đức

**Trướng Đai họ Y Hà Nội

Chịu trách nhiệm chính: Đinh Ngọc Anh

Email: anhdn.dr@gmail.com

Ngày nhân bài: 28.10.2021

Ngày phản biện khoa học: 20.12.2021

Ngày duyệt bài: 30.12.2021
}

\section{Đinh Ngọc Anh*, Vũ Thị Bích Hạnh**}

sau phẫu thuật nội soi khâu rách chóp xoay khớp vai tai Bệnh viện Việt Đức từ 7/2020-5/2021. Đánh giá bằng Thang điểm khớp vai của Đại học California Los Angeles (UCLA) và đo tâm vận động khớp, thử cơ bằng tay. Người bệnh tập theo chương trình của Đại học California Los Angeleș. Người bệnh được tập tại viện từ ngày thứ 2 sau phâu thuật sau đó được hướng dẫn tập tại nhà có theo dõi đánh giá sau 3 tuần, 6 tuần và 12 tuần. Kết quả: Chức năng khớp vai sau phẫu thuật nội soi và phục hồi chức năng có sự tiến triển rõ rệt sau 3-6 và 12 tuần. Điểm UCLA trung bình đạt từ 11,98 tăng lên 26,07 (tối đa là 33 điểm). Cơ lực nhóm cơ chóp xoay và tầm vân đônng khớp vai sau 12 tuần đều được cải thiện có ý nghĩa. Kết luận: 
Chương trình tập khớp vai hiện được áp dụng ở Bệnh viên Viêt Đức có tác dung cao trong cải phục hôi chức năng khớp vai sau phẫu thuật nội soi rách chóp xoay.

Tư khóa: phấu thuât nội soi, rách chóp xoay, phục hồi chức năng

\section{SUMMARY}

\section{THE RESULTS OF REHABILITATION OF THE SHOULDER AFTER ENDOSCOPIC SURGERY ON ROTATOR CUP'S RUPTURE}

Objective: to assessment the results of shoulder rehabilitation following endoscopic surgery on rotator cup's rupture. Method: An interventional longitudinal study without controlled group has been implemented. All of the patients operated endoscopically to repair the rotator cup tendons in Viet Duc Hospital from $7 / 2020$ - 5/2021 matching the choosing items had been selected. They were 58 persons. The University California Los Angeles scale (UCLA) and Measure of shoulder range of motion, muscles strength has been used to evaluate the shoulder functions. Two days after the surgery, the patients had have exercises training until leave the hospital and then follow they training at home with instructions. Re-assessment had been carried out on $3^{\text {th }}, 6^{\text {th }}$ and $12^{\text {th }}$ weeks after surgery. Results: The shoulder functions following endoscopic surgery and exercises training had achieved a significant progression after 3-6 and 12 weeks by UCLA scale, average points had increased from 11,98 to 26,07 points ( $\max$ is $33 p t s$ ). At the same time, the muscle's strength of rotator cuff and range of motion of shoulder had improved significantly. Conclusion: The actual exercise training program at VietDuc Hospital had good effect in rehabilitation of shoulder function following endoscopic repairing of the rotator cuff's rupture.

Key words: arthroscopic surgery, rotator cuff's rupture, rehabilitation.

\section{I. ĐĂT VẤN ĐỀ}

Chóp xoay là tên gọi phần gân bám vào đầu trên xương cánh tay của bốn cơ bao gồm cơ dưới vai, cơ trên gai, cơ dưới gai và cơ tròn bé. Rách chóp xoay ảnh hưởng đến khoảng $4 \%$ đến $32 \%$ dân số và xuất hiện gia tăng theo độ tuổi [1], gây đau và hạn chế vận đông khớp vai. Ngoài điều trị bảo tồn, điều trị phẫu thuật được đặt ra khi điêu trị bảo tồn không thành công, rách chóp xoay gây đau, yếu vai, khiến người bệnh không thể dạng hoặc gấp chủ động hết tầm vận động. Tại Viện Chấn thương chỉnh hình bệnh viện Việt Đưúc, phẫu thuật nội soi khâu chóp xoay đã được áp dụng và triển khai trong nhiều năm nay. Việc phục hồi chức năng sau phẫu thuật khâu chóp xoay là rất quan trọng trong quá trình phục hồi chức năng khớp vai, giúp người bệnh cải thiện mức độ đau và vận động khớp vai; đồng thời tránh biến chứng cứng khớp vai do bất động. Hiện ở Viêtt Nam chưa có báo cáo nào về kết quả phục hồi chức năng sau phẫu thuật khâu chóp xoay. Do vậy. chúng tôi thực hiện nghiên cứu này nhằm đánh giá kết quả lâm sàng của phục hồi chức năng cho người bệnh sau phẫu thuật nội soi khâu chóp xoay khớp vai.

\section{II. ĐốI TƯỢNG VÀ PHƯƠ'NG PHÁP NGHIÊN CỨU}

Đối tượng: các bệnh nhân được chẩn đóan rách chóp xoay và được phẫu thuật nội soi khâu chóp xoay khớp vai. Bằng phương pháp can thiệp tiến cứu, không có nhóm chứng, toàn bộ người bệnh được phẩu thuật nội soi khâu chóp xoay tại Viện Chấn thương Chỉnh hình Việt Đức trong thời gian từ tháng 07/2020 đến tháng 05/2021 được chọn vào nghiên cứu. Tổng số là 58 người bệnh.

Tiêu chuẩn lựa chọn: người bênh trên 18 tuổi, được chẩn đoán rách chóp xoay khớp vai và đã được phẫu thuật nội soi khâu chóp xoay khớp vai và đồng ý tham gia nghiên cứu và tuân thủ quy trình điêu trị.

Tiêu chuẩn loại trừ: người bệnh được chẩn đoán rách chóp xoay kèm theo các tổn thương khác ở khớp vai: Rách gân cơ chóp xoay trong một bệnh lý cơ xương khớp hệ thống: viêm khớp dạng thấp, lupus ban đỏ, hoặc bệnh lý khớp viêm mạn tính có từ trước đó. Các trường hợp đau và hạn chế vận động khớp vai trước phẫu thuật không do chấn thương; người bệnh không có các tổn thương kèm theo, không có rối loạn nhận thức người bệnh được thu thập thông tin và khám lâm sàng và có phim cộng hưởng từ khớp vai, lượng giá chức năng khớp vai sau phẫu thuật 2 ngày bằng thang điểm Thang điểm khớp vai của Đại học California Los Angeles (UCLA) được phát triển vào năm 1981. Thang điểm vai là sự kết hợp giữa các kết quả khám thực thể (gập khớp vai chủ động từ $0-5$ điểm và cơ lực gập khớp vai từ 0-5 điểm) và các đánh giá chủ quan của người bệnh (mức độ đau từ 1-8 điểm, sự hài lòng từ 0-5 điểm và tự đánh giá chức năng từ 1-10 điểm). Đau và chức năng ưu tiên được 20 trong số 35 điểm tổng số. Cách cho điểm: từ 34-35 điểm- "rất tốt". Từ 28-33 điểm"tốt"; Từ 21-27 điểm- "trung bình"; Từ 0-20 điểm- "xấu".

Ngoài ra chức năng khớp vai còn được đánh giá bằng tầm vận động khớp theo phương pháp Zero và cơ lực các cơ chóp xoay theo bâc thử cơ ( 0 điểm- liêt hoàn toàn và 5 điểm- cơ lực bình thường). người bệnh tập theo chương trình của Đại học California Los Angeles. tập tại viện sau đó được hướng dẫn tập tại nhà có theo dõi đánh giá sau 3 tuần, 6 tuần và 12 tuần. Qui trình tập 
PHCN chia làm 5 giai đoạn:

Giai đoạn I: từ ngày đầu đến 3 tuần: đeo đai cố định khớp vai, tập thụ động gấp và dạng vai đến $90^{\circ}$, xoay ngoài đến $30^{\circ}$

Giai đoạn II: tuần thứ 3 đến 6 , gấp và dạng vai chủ động có trợ giúp đến $150^{\circ}$

Giai đoạn III: tuần 7 đến 9 , vận động chủ động và chủ động có trợ giúp đến hết tẩm. Tập xoay ngoài đến $90^{\circ}$.

Giai đoạn IV: 9 đến 12 tuần, lấy lại cơ lực bậc 3 - 4 của cơ chóp xoay

\section{KẾT QUẢ NGHIÊN CỨU}

3.1. Đặc điểm đối tượng nghiên cứu $(n=58)$

Bảng 1. Đặc điểm đổi tượng nghiên cứu

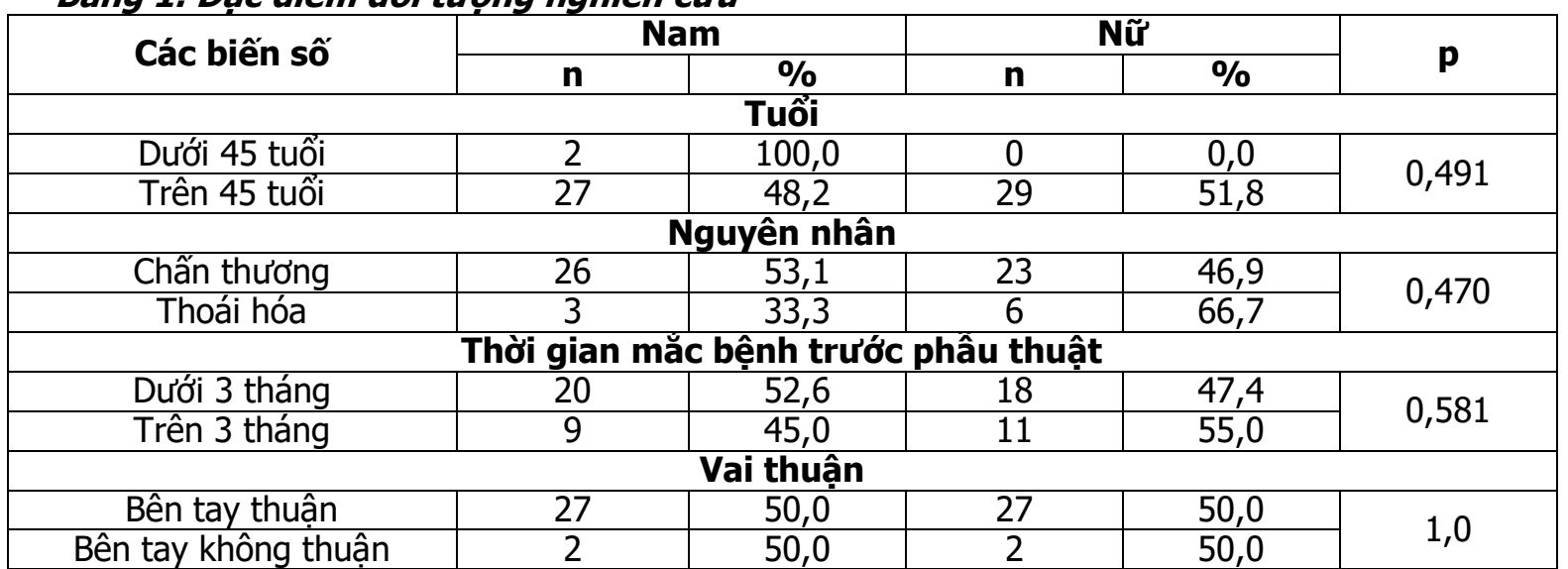

Nhận xét: Nghiên cứu chúng tôi có 58 bệnh nhân, tỉ lệ nam: nữ là $1: 1$. Trong nhóm bệnh nhân nam và nhóm bệnh nhân nữ thì nhóm tuổi 55-64 chiếm tỷ lệ cao nhất (lần lượt là 48,3\% $58,6 \%)$, nhóm tuổi <35 chiếm tỷ lệ thấp nhất (lần lượt là 6,9\% - 0\%).

Sự khác biệt giữa các nhóm bệnh nhân phân bố nhóm tuổi theo giới không có ý nghĩa thống kê với $\mathrm{p}>0.05$.

Giai đoạn V: từ tháng 3 đến tháng 6 , phục hồi toàn bộ tầm vận động và cơ lực khớp vai.

Xử lý số liệu: Nhẩp số liệu, phân tích và xử lý số liệu bằng phần mềm SPSS 25.0.

Kết quả được thể hiện dưới dạng: Giá trị trung bình, độ lệch chuẩn, tỷ lệ \%.

Các phép toán sử dụng : Test X2 (so sánh 2 tỷ lệ), test T-student (so sánh 2 giá trị trung bình).

Kết quả nghiên cứu được coi là có ý nghĩa thống kê khi $p<0,05$.

Bảng 2. Sự cải thiện chức năng khớp vai theo điểm UCLA sau phục hồi chức năng

\begin{tabular}{|c|c|c|c|c|}
\hline Thời điểm sau mổ Điếm UCLA & Trung bình & Điểm nhỏ nhất & Điểm lớn nhất & $\mathbf{p}$ \\
\hline 3 tuần & $11,98 \pm 0,13$ & 11 & 12 & \multirow{3}{*}{$<0,001$} \\
\hline 6 tuần & $15,95 \pm 1,07$ & 14 & 21 & \\
\hline 12 tuần & $26,07 \pm 2,69$ & 21 & 33 & \\
\hline
\end{tabular}

Nhân xét: Sự cải thiện chức năng khớp vai theo điểm UCLA theo thời gian là khác biệt có ý nghĩa thống kê với $p<0,001$. Sự cải thiện này được minh họa ở biểu đồ dưới đây.

Bảng 3. Sự cải thiện tâm vận động khớp vai sau phục hồi chức năng

\begin{tabular}{|c|c|c|c|c|}
\hline $\begin{array}{c}\text { Tâmm vận } \\
\text { động khớp }\end{array}$ & $\begin{array}{c}\text { Sau 3 tuần } \\
\mathbf{X} \pm \text { SD (độ) (1) }\end{array}$ & $\begin{array}{c}\text { Sau 6 tuần } \\
\mathbf{X} \pm \text { SD (độ) (2) }\end{array}$ & $\begin{array}{c}\text { Sau 12 tuần } \\
\mathbf{X} \pm \text { SD (độ) (3) }\end{array}$ & $\mathbf{p}$ \\
\hline Dạng vai & $80 \pm 7,3$ & $125 \pm 6,7$ & $166,0 \pm 5,9$ & $\begin{array}{l}\mathrm{p}(1-2)<0,001 \\
\mathrm{p}(1-3)<0,001 \\
\mathrm{p}(2-3)<0,001\end{array}$ \\
\hline Gập vai & $80 \pm 8,7$ & $150,1 \pm 5,6$ & $171,3 \pm 3,1$ & $\begin{array}{l}\mathrm{p}(1-2)<0,001 \\
\mathrm{p}(1-3)<0,001 \\
\mathrm{p}(2-3)<0,001\end{array}$ \\
\hline
\end{tabular}


VIETNAM MEDICAL JOURNAL N01 - JANUARY - 2022

\begin{tabular}{|c|c|c|c|c|}
\hline Xoay trong & $56,9 \pm 4,3$ & $61,2 \pm 4,3$ & $80 \pm 3,7$ & $\begin{array}{l}\mathrm{p}(1-2)<0,001 \\
\mathrm{p}(1-3)<0,001 \\
\mathrm{p}(2-3)<0,001\end{array}$ \\
\hline Xoay ngoài & $20 \pm 6,0$ & $48,2 \pm 5,6$ & $68,3 \pm 5,3$ & $\begin{array}{l}\mathrm{p}(1-2)<0,001 \\
\mathrm{p}(1-3)<0,001 \\
\mathrm{p}(2-3)<0,001\end{array}$ \\
\hline
\end{tabular}

Nhận xét: Tầm vận động khớp vai sau 3-6 và 12 tuần đều có sự cải thiện có ý nghĩa thống kê với $\mathrm{p}<0,001$

Bảng 4. Cải thiện cơ lực các cơ chóp xoay

\begin{tabular}{|c|c|c|c|c|}
\hline Các cơ & $\begin{array}{l}\text { Sau } 3 \text { tuân } \\
\text { (Bậc cơ) (1) }\end{array}$ & $\begin{array}{l}\text { Sau } 6 \text { tuân } \\
\text { (Bậc cơ) (2) }\end{array}$ & $\begin{array}{l}\text { Sau } 12 \text { tuân } \\
\text { (Bậc cơ) (3) }\end{array}$ & $\mathbf{p}$ \\
\hline Trên gai & $1 \pm 0,0$ & $2,08 \pm 0,27$ & $3,36 \pm 0,49$ & $\begin{array}{c}\mathrm{p}(1-2)<0,001 ; \mathrm{p}(1-3)<0,001 \\
\mathrm{p}(2-3)<0,001\end{array}$ \\
\hline Dưới gai & $1 \pm 0,0$ & $2,08 \pm 0,27$ & $3,44 \pm 0,50$ & $\begin{array}{c}\mathrm{p}(1-2)<0,001 ; \mathrm{p}(1-3)<0,001 \\
\mathrm{p}(2-3)<0,001\end{array}$ \\
\hline Dưới vai & $2,28 \pm 0,46$ & $3,31 \pm 0,48$ & $4,28 \pm 0,60$ & $\begin{array}{c}\mathrm{p}(1-2)<0,001 ; \mathrm{p}(1-3)<0,001 \\
\mathrm{p}(2-3)<0,001\end{array}$ \\
\hline Tròn bé & $1 \pm 0,0$ & $2,08 \pm 0,27$ & $3,44 \pm 0,50$ & $\begin{array}{c}\mathrm{p}(1-2)<0,001 ; \quad \mathrm{p}(1-3)<0,001 \\
\mathrm{p}(2-3)<0,001\end{array}$ \\
\hline
\end{tabular}

Nhận xét: Sự cải thiện cơ lực nhóm cơ chóp xoay sau 3-6 và 12 tuần là có ý nghĩa thống kê với $\mathrm{p}<0,001$

\section{BÀN LUẬN}

4.1. Đặc điểm người bệnh: Nghiên cứu thực hiện đánh giá trên 58 người bệnh có tổn thương rách chóp xoay khớp vai với tỷ lẹ nam: nữ $=1: 1$. Tuy nhiên, kết quả nghiên cứu của chúng tôi cũng có sự khác biệt với nghiên cứu của Tăng Hà Nam Anh [2] đánh giá 144 người bệnh rách chóp xoay phẩu thuật nội soi với tỷ lệ nam:nữ $=1,37$ [6]. Sự khác biệt có thể do thời điểm tiến hành nghiên cứu hoặc cõ mẫu nghiên cứu của tác giả Tăng Hà Nam Ảnh $(n=144)$ lớn hơn nghiên cứu của chúng tôi $(n=58)$. Kết quả này tương đồng với nghiên cứu của P.Vora và cộng sự [3], Sabo M.T [4] và cộng sự không có sự khác biệt đáng kể về giới tính của người bênh bị tổn thương chóp xoay khớp vai. Hồi cứu lại y văn, chúng tôi không thấy có yếu tố nào dễ gây tổn thương khớp vai hơn giữa hai giới nam và nữ nếu không có chấn thương. Như vậy tỷ lệ nam nhiều hay nữ nhiều hơn chỉ là tình cờ và không thể kết luận được giới tính là yếu tố nguy cơ gây ra rách chóp xoay.

Trong nghiên cứu chúng tôi, tỷ lệ người bệnh rách chóp xoay chủ yếu tập trung ở nhóm người bệnh từ 45 tuổi đến 65 tuổi và chiếm 72,4\%. Theo Nguyễn Hữu Mạnh [6] và cộng sự nghiên cứu điều trị rách chóp xoay khớp vai bằng nội soi trên 42 người bệnh tại Bệnh viện Đại học Y Hà Nội và Bệnh viện đa khoa Xanh Pôn có độ tuổi trung bình là $59,10 \pm 8,53$ (36-76 tuổi) với độ tuổi $\geq 45$ là chủ yếu (chiếm 95,2\%) [6]. Các tác giả cho rằng nguyên nhân của rách chóp xoay chủ yếu là tình trạng thoái hóa gân, sử dụng vai nhiều, thiếu máu nuôi và sự co sát khoang dưới mỏm cùng ở người bệnh trung niên và cao tuổi. Trong khi khai thác bênh sử, có 6 người bênh tuổi từ 35 đến 49 có triệu chứng đau và hạn chế vận động sau chấn thương vào vùng vai. Các người bệnh còn lại chúng tôi thường có tiền căn chấn thương rất nhẹ và gần như người bệnh cũng không nhớ rằng mình đã có tiền căn chấn thương trước đó. Điều này chúng tỏ cơ chế chấn thương chỉ là yếu tố phụ trên nền một gân chóp xoay đã bi thoái hóa và rách sẵn hoặc đã có nguy cơ rách sẵn. Với lập luận như trền có thể nghĩ rằng tuổi cao là 1 yếu tố tiên lượng không tốt với lành gân và cải thiện hoạt động chức năng sau mổ giảm theo thời gian.

Trong nghiên cứu của chúng tôi, tổn thương chóp xoay khớp vai thường ở bên vai phải tương ứng với các người bênh thuân tay phải. Cu thể, trong số 54 người bệnh thuận tay phải thì có tới $53 / 54$ người bênh $(98,1 \%)$ tổn thương chóp xoay tại vai phải. Trong khi đó, trong số 4 người bênh thuận tay trái thì chỉ có $50 \%$ người bênh bị tổn thương chóp xoay tại vai trái. Sự khác biệt có ý nghĩa thống kê với với $p<0,01$. Kết quả này tương đồng với kết quả nghiên cứu của Sayampanathan $A A$ và cộng sự tiến hành tổng quan hệ thống các yếu tố nguy cơ của tổn thương chóp xoay khớp vai với tổn thương chóp xoay khớp vai ở tay thuận cao hơn gấp 2,3 lần so với tay không thuận (95\%CI: 1,01-5,25).

Người bệnh trong nghiên cứu bị rách gân chóp xoay là $100 \%$ là rách gân cơ trên gai. Điều này cũng phù hợp với nghiên cứu của Nguyễn Hữu 
Mạnh và cộng sự. Trong nghiên cứu của Nguyễn Hữu Mạnh cho thấy gân trên gai là tổn thương hay gặp nhất chiếm tỷ lệ 97,6\%; chỉ 3 trường hợp có tổn thương gân dưới vai chiếm tỷ lê 7,14\%.

4.2. Diễn biến chức năng khớp vai sau phục hồi chức năng theo thời gian. Phân tích thời gian hồi phục khớp vai sau phục hồi chức năng trong thời gian 12 tuần cho thấy điểm UCLA có sự cải thiện rõ rệt, đánh giá tầm vận động khớp vai có tiến triển với $p<0,001$ có ý nghĩa thống kê và cơ lực nhóm cơ chóp xoay có sư tiến triển từ bâc 1 taii 3 tuần đến bậc $4 / 5$ tai 12 với $p<0,01$ có ý nghĩa thống kê. Trong nghiên cứu của Phan Đình Mừng [7] cũng cho thấy kết quả phục hồi chức năng có tiến triển trong 3 tháng đầu và tiếp tục tiến triển tối đa trong 12 tháng tiếp theo sau đó không thay đổi nhiều ở năm tiếp theo. Nghiên cứu của Charousset [6] và cộng sự xác định có sự cải thiện của chức năng khớp vai trong 3 tháng đầu và tiếp tục tiến triển trong năm đầu sau phẩu thuật.

Điều này cho thấy phục hồi chức năng đóng vai trò quan trọng trong quá trình phục hồi chức năng khớp vai sau phẫu thuật nội soi khâu chóp xoay.

\section{KẾT LUẦN}

Chức năng khớp vai sau phẫu thuật nội soi khâu chóp xoay được phục hồi chức nằng trong 12 tuần có sự tiến triển rõ̃ rệt. Sự khác biệt có ý nghĩa thống kê. Chỉ số UĆLA trung bình đạt 26,07 và tối đa là 33 . Cơ lực nhóm cơ chóp xoay bao gồm cơ trên gai, cơ dưới gai, tròn bé, cơ dưới vai tăng lần lượt là $3,36 \pm 0,49 ; 3,44 \pm$ 0,$50 ; 3,44 \pm 0,50 ; 4,28 \pm 0,60$ sau 12 tuần. Tầm vận động khớp vai sau 12 tuần dạng đạt $166,0 \pm$ 5,9 , gấp đạt $171,3 \pm 3,1$, xoay trong $80 \pm 3,7$ và xoay ngoài đạt $68,3 \pm 5,3$.

\section{TÀI LIỆU THAM KHẢO}

1. Lin, J.C., Weintraub, N. Aragaki, D.R. Nonsurgical treatment for rotator cuff injury in the elderly. J Am Med Dir Assoc. 2008.05.003. 9(9): 626-32. 10.1016.

2. Tăng Hà Nam Anh. Kết quả điều trị rách chóp xoay qua nội soi, Luân án Tiến sỹ y học. 2014.

3. Dr. Padmanabh Vora, Dr. Vihang Shah, Dr. Nisarg Patel, Dr. Chirag Chudasama, Dr. Manish Shah and Dr. Mukund Prabhakar. Results of arthroscopic rotator cuff repair. International Journal of Orthopaedics Sciences. 2018; Volume 4 Issue 1.

4. Sabo M.T, LeBlanc J, Hildebrand K.A (2021). Patient gender and rotator cuff surgery: are there differences in outcome? BMC Musculoskelet Disord.2021; 22(1), 838.

5. Nguyê̂n Hữu Manh, Trân Trung Dũng, Lê Khánh Trình (2020). Điêu trị rách chóp xoay bằng kỹ thuât khâu gân Mason Allen cải biên qua nội soi. Tap chí Nghiên cứu Y học. 2020; 132(8), 84-94.

6. Christophe Charousset 1, Jean Grimberg, Louis Denis Duranthon, Laurence Bellaïche, David Petrover, Kunal Kalra. The time for functional recovery after arthroscopic rotator cuff repair: correlation with tendon healing controlled by computed tomography arthrography. Arthroscopy. 2008 Jan;24(1):25-33. doi: 10.1016/j.arthro.2007.07.023. Epub 2007 Nov 19.

7. Phan Đinh Mững. Kết quả phuc hồi chức năng khớp vai sau phấu thuât nội soi khâu chóp xoay tại bệnh viện 175. Tạp chí Y học Việt Nam. 2018.

\title{
PHẪU THUÂTT SỬ DỤNG OMNIPORE ĐIỀU TRI KHE HỞ' XƯO'NG ỨC Ở TRẺ EM: NHÂN 3 TRƯỜNG HỢP
}

\author{
Tô Mạnh Tuân ${ }^{1}$, Nguyễn Minh Khôi ${ }^{1}$, Phạm Duy Hiền ${ }^{1}$ \\ Vũ Thanh Tú1, Đặng Hanh Tiệp ${ }^{1}$, Đặng Ánh Dương ${ }^{1}$, \\ Trần Thị Tuyến ${ }^{1}$, Lê Thị Lý ${ }^{1}$, Nguyền Minh Huyền', Nguyễn Văn Sáng1
}

\section{TÓM TẮT}

Đặt vấn đề: Khe hở xương ức là một dị dạng thành ngực hiếm gặp, xảy ra do sự liền không hoàn toàn của xương ức trong thời kì bào thai. Tỉ lệ mắc $1: 100000$ trẻ sinh sống và chiếm dưới $1 \%$ các trường hợp dị dạng lồng ngực. Phẫu thuật cần được thực hiện nhẳm phục hồi cấu trúc giải phẫu, chức năng lồng

*Bênh viên Nhi Trung ương

Chịu trách nhiệm chính: Tô Mạnh Tuân

Email: tuannhpsep2007@gmail.com

Ngày nhận bài: 19.10.2021

Ngày phản biện khoa học: 21.12.2021

Ngày duyệt bài: 27.12.2021 ngực và giảm nguy cơ nhiễm trùng. Phẫu thuâtt nên được thực hiện trong giai đoạn sơ sinh và trẻ nhũ nhi vì sự linh hoạt của thành ngực là tối đa. Phẫu thuật có thể sử dụng trực tiếp với vạt màng sụn, trượt ghép sụn hay mảnh cơ ghép hay các vật liệu nhân tạo như Omnipore (Matrix Surgical USA-Atlanta, Georgia 30349 U.S.A.). Nghiên cứu này ${ }_{k}$ chúng tôi đánh giá kết quả ứng dụng Omnipore phấu thuật nhân 3 bệnh nhân khe hở xương ức tại Bệnh viện Nhi Trung ương. Ca bệnh: Ba ca bệnh là trẻ nam, tuổi 1-1-12 tháng, có khe hở toàn bô xương ức ở 2 trẻ và môt trẻ có khe hở hình chữ $V$ ngược, được phẫu thuật tạo hình xương ức có sử dựng mảnh ghép Omnipore. Kết quả khám lai sau phấu thuật 1 tháng, 3 tháng, 12 tháng cho thấy kết quả xương liền, không biến chứng. Kết Luận: Khe 